\title{
TRANSPORTATION MANAGEMENT IN A DISTRIBUTED LOGISTIC CONSUMPTION SYSTEM UNDER UNCERTAINTY CONDITIONS
}

\author{
Lev Raskin \\ Department of Distributed information systems and cloud technologies \\ National Technical University "Kharkiv Polytechnic Institute" \\ 2 Kyrpychova str., Kharkiv, Ukraine, 61002 \\ Oksana Sira \\ Department of Distributed information systems and cloud technologies \\ National Technical University "Kharkiv Polytechnic Institute" \\ 2 Kyrpychova str., Kharkiv, Ukraine, 61002 \\ topology@ukr.net \\ Viacheslav Karpenko \\ Department of Distributed information systems and cloud technologies \\ National Technical University "Kharkiv Polytechnic Institute" \\ 2 Kyrpychova str., Kharkiv, Ukraine, 61002 \\ ncdiplom@gmail.net
}

\begin{abstract}
The problem of supply management in the supplier-to-consumer logistics transport system has been formed and solved. The novelty of the formulation of the problem consists in the integrated accounting of costs in the logistic system, which takes into account at the same time the cost of transporting products from suppliers to consumers, as well as the costs for each of the consumers to store the unsold product and losses due to possible shortages. The resulting optimization problem is no longer a standard linear programming problem. In addition, the work assumes that the solution of the problem should be sought taking into account the fact that the initial data of the problem are not deterministic. The analysis of traditional methods of describing the uncertainty of the source data. It is concluded that, given the rapidly changing conditions for the implementation of the delivery process in a distributed supplier-to-consumer system, it is advisable to move from a theoretical probability representation of the source data to their description in terms of fuzzy mathematics. At the same time, in particular, the fuzzy values of the demand for the delivered product for each consumer are determined by their membership functions.

Distribution of supplies in the system is described by solving a mathematical programming problem with a nonlinear objective function and a set of linear constraints of the transport type. In forming the criterion, a technology is used to transform the membership functions of fuzzy parameters of the problem to its theoretical probabilistic counterparts - density distribution of demand values. The task is reduced to finding for each consumer the value of the ordered product, minimizing the average total cost of storing the unrealized product and losses from the deficit. The initial problem is reduced to solving a set of integral equations solved, in general, numerically. It is shown that in particular, important for practice, particular cases, this solution is achieved analytically.

The paper states the insufficient adequacy of the traditionally used mathematical models for describing fuzzy parameters of the problem, in particular, the demand. Statistical processing of real data on demand shows that the parameters of the membership functions of the corresponding fuzzy numbers are themselves fuzzy numbers. Acceptable mathematical models of the corresponding fuzzy numbers are formulated in terms of bifuzzy mathematics. The relations describing the membership functions of the bifuzzy numbers are given. A formula is obtained for calculating the total losses to storage and from the deficit, taking into account the bifuzzy of demand. In this case, the initial task is reduced to finding the distribution of supplies, at which the maximum value of the total losses does not exceed the permissible value.
\end{abstract}

Keywords: production-consumption logistic system, transportation problem, fuzzy and bifuzzy demand, optimization of fuzzy criteria. 


\section{Introduction}

The canonical transport problem of linear programming is formulated as follows [1-4].

Let there be $\mathrm{m}$ points of production of a certain product and $\mathrm{n}$ points of its consumption. Production and consumption are balanced, i. e. total production and consumption are equal. The task is in finding a rational transportation plan from production points to consumption points, at which transport costs are minimal. The resulting transportation plan must meet the following requirements:

1) demand of each of the points of consumption must be fully met;

2) all the product produced at each production point must be used.

Let's formalize the task. Let's introduce the following notation:

$x_{i j}$ - the number of units of the product transported from the $i$-th point of production to the $j$-th point of consumption;

$c_{i j}$ - the cost of transporting a unit of product from the $i$-th point to the $j$-th;

$a_{i}$ - the number of units of product produced in the $i$-th point;

$b_{j}$ - the number of units of product consumed in $j$-th point.

In the accepted notation, the problem is reduced to finding a set of variables $\left\{x_{i j}\right\}, i=1,2, \ldots, n$, minimizing the objective function

$$
L\left(\left\{x_{i j}\right\}\right)=\sum_{i=1}^{m} \sum_{j=1}^{n} c_{i j} x_{i j}
$$

and satisfying the constraints

$$
\begin{gathered}
\sum_{i=1}^{m} x_{i j}=b_{j}, \quad j=1,2, \ldots, n ; \\
\sum_{j=1}^{n} x_{i j}=a_{i}, \quad i=1,2, \ldots, m ; \\
x_{i j} \geq 0, \quad i=1,2, \ldots, m ; \quad j=1,2, \ldots, n .
\end{gathered}
$$

In the system of the assumptions made here, the most rigid and almost always broken is the assumption that the magnitude of the demand at each of the consumption points is precisely known. In this regard, it is much more natural to assume that there is uncertainty about the values $b_{j}, j=1,2, \ldots, n$. Its character may be different. If for each point of consumption a preliminary sampling of the demand values is obtained, then its standard statistical processing within the framework of the theoretical probabilistic approach allows to obtain the distribution density of the observed quantity of demand and its moments. In practice, this is not the case: the available data are sufficient only to obtain satisfactory estimates of the range of possible values of demand at each point and its mathematical expectation. This circumstance leads to the expediency of using a fuzzy mathematics apparatus to describe the transportation system [5-9]. Let's formulate the formulation and solve the transportation problem under conditions when the demand at the points of consumption is not clearly defined [10].

\section{Mathematical model of transportation management under fuzzy demand}

Taking this into account, let's introduce a description of the possible demand values at the points of consumption $b_{j}$ by membership functions $\phi_{j}\left(b_{j}\right), j=1,2, \ldots, n$. Some freedom that emerges in this case when selecting the order quantity of a product $z_{j}$ has an important advantage, since it allows to take into account differences in the amount of losses in case of an unsuccessful selection of the order value. Let's introduce:

$R_{1}\left(z_{j}\right)$ - the magnitude of the losses occurring in cases where the order $z_{j}$ exceeds the demand and there is a need to store unsold product;

$R_{2}\left(z_{j}\right)$ - the magnitude of the losses that occur if the demand $b_{j}$ at a particular $\mathrm{j}$-th sales point of the product exceeds the order $z_{j}$ and as a result there are losses from the shortage. 
It is clear that in this situation the set of values $z_{j}, j=1,2, \ldots, n$, must be chosen in some reasonable way. In this regard, the initial formal formulation of the problem is converted to the following: find sets $Z=\left(z_{j}\right)$ and $X(Z)=\left\{x_{i j}\left(\left(z_{j}\right)\right\}\right.$, and minimizing

$$
L\left(x_{i j}\left(z_{j}\right)\right)=\sum_{j=1}^{n} R_{1}\left(z_{j}\right)+\sum_{j=1}^{n} R_{2}\left(z_{j}\right)+\sum_{i=1}^{m} \sum_{j=1}^{n} c_{i j} x_{i j}\left(z_{j}\right)
$$

and satisfying the constraints

$$
\begin{gathered}
\sum_{j=1}^{n} x_{i j}\left(z_{j}\right)=a_{i}, \quad i=1,2, \ldots, m, \\
\sum_{i=1}^{m} x_{i j}\left(z_{j}\right)=z_{j}, \quad j=1,2, \ldots, n, \\
\sum_{j=1}^{n} z_{j}=\sum_{i=1}^{m} a_{i}, \\
x_{i j}\left(z_{j}\right) \geq 0, \quad i=1,2, \ldots, m, \quad j=1,2, \ldots, n .
\end{gathered}
$$

Let's obtain an analytic description of the functions, $R_{1}\left(z_{j}\right)$ and $R_{2}\left(z_{j}\right), j=1,2, \ldots, n$. Since $z_{j}$ - fuzzy numbers, then any of their functions is also a fuzzy number. Using membership functions $\phi_{j}\left(b_{j}\right)$, let's introduce functions

$$
\tilde{\phi}_{j}\left(b_{j}\right)=\frac{\phi_{j}\left(b_{j}\right)}{\int_{G_{j}} \phi\left(b_{j}\right) d b_{j}}, j=1,2, \ldots, n
$$

where $G_{j}$ - the range of possible values

The obtained functions $\tilde{\phi}_{j}\left(b_{j}\right)$ have all the properties of the density distribution of random variables: they are non-negative and satisfy the normalization condition, that is,

$$
\int_{G_{j}} \tilde{\phi}\left(b_{j}\right) d b_{j}=1, \quad j=1,2, \ldots, n
$$

Then the function $\phi_{j}\left(b_{j}\right)$ can be used to calculate the expected value of a fuzzy number $z_{j}$.

$$
m_{j}=\int_{G_{j}} b_{j} \tilde{\phi}\left(b_{j}\right) d b_{j}, \quad j=1,2, \ldots, n
$$

which is a natural analogue of the expectation value of a random variable defined in probability theory using its density.

In this case, the expected value of the cost of storing the unrealized part of the product will be equal to

$$
R_{1}\left(z_{j}\right)=\alpha_{j} \int_{0}^{z_{j}}\left(z_{j}-b_{j}\right) \tilde{\phi}\left(b_{j}\right) d b_{j}
$$

where $\alpha_{j}$ - the average cost of storing a unit of product in $j$-th sales point, $j=1,2, \ldots, n$.

Similarly, let's define the average losses from the deficit

$$
R_{2}\left(z_{j}\right)=\beta_{j} \int_{z_{j}}^{\infty}\left(b_{j}-z_{j}\right) \tilde{\phi}\left(b_{j}\right) d b_{j}
$$


where $\beta_{j}$ - the average profit derived from the sale of a unit of product in the $j$-th sales point, $j=1,2, \ldots, n$.

The obtained relations (12) and (13) can be used to independently calculate rational values $z_{j}$ for each of the sales points, minimizing the total storage costs of the unsold part of the product and the loss from the deficit in this particular item. To this end, for the $j$-th sales point let's introduce

$$
\begin{gathered}
R_{j}\left(z_{j}\right)=R_{1}\left(z_{j}\right)+R_{2}\left(z_{j}\right)=\alpha_{j} \int_{0}^{z_{j}}\left(z_{j}-b_{j}\right) \tilde{\phi}_{j}\left(b_{j}\right) d b_{j}+\beta_{j} \int_{z_{j}}^{\infty}\left(b_{j}-z_{j}\right) \tilde{\phi}_{j}\left(b_{j}\right) d b_{j}= \\
\alpha_{j} z_{j} \int_{0}^{z_{j}} \tilde{\phi}_{j}\left(b_{j}\right) d b_{j}-\alpha_{j} \int_{0}^{z_{j}} b_{j} \tilde{\phi}_{j}\left(b_{j}\right) d b_{j}+\beta_{j} \int_{z_{j}}^{\infty} b_{j} \tilde{\phi}_{j}\left(b_{j}\right) d b_{j}-\beta_{j} z_{j} \int_{z_{j}}^{\infty} \tilde{\phi}_{j}\left(b_{j}\right) d b_{j}, \\
j=1,2, \ldots, n .
\end{gathered}
$$

Now let's find a rational value $z_{j}$ by differentiating $R_{j}\left(z_{j}\right)$ in $z_{j}$, equating its result to zero and solving this equation. Because

$$
\begin{gathered}
\frac{d}{d z_{j}} \int_{0}^{z_{j}} \tilde{\phi}_{j}\left(b_{j}\right) d b_{j}=\tilde{\phi}_{j}\left(z_{j}\right), \frac{d}{d z_{j}} \int_{z_{j}}^{\infty} \tilde{\phi}_{j}\left(b_{j}\right) d b_{j}=-\tilde{\phi}_{j}\left(z_{j}\right), \\
\frac{d}{d z_{j}} \int_{0}^{z_{j}} b_{j} \tilde{\phi}_{j}\left(b_{j}\right) d b_{j}=z_{j} \tilde{\phi}_{j}\left(z_{j}\right), \frac{d}{d z_{j}} \int_{z_{j}}^{\infty} b_{j} \tilde{\phi}_{j}\left(b_{j}\right) d b_{j}=-z_{j} \tilde{\phi}_{j}\left(z_{j}\right),
\end{gathered}
$$

then

$$
\begin{gathered}
\frac{d R_{j}\left(z_{j}\right)}{d z_{j}}=\alpha_{j} \int_{0}^{z_{j}} \tilde{\phi}_{j}\left(b_{j}\right) d b_{j}+\alpha_{j} z_{j} \tilde{\phi}_{j}\left(z_{j}\right)-\alpha_{j} z_{j} \tilde{\phi}_{j}\left(z_{j}\right)-\beta_{j} z_{j} \tilde{\phi}_{j}\left(z_{j}\right)-\beta_{j} \int_{z_{j}}^{\infty} \tilde{\phi}_{j}\left(b_{j}\right) d b_{j}+b_{j} z_{j} \tilde{\phi}_{j}\left(z_{j}\right)= \\
\quad \alpha_{j} \int_{0}^{z_{j}} \tilde{\phi}_{j}\left(b_{j}\right) d b_{j}-\beta_{j}\left(1-\int_{0}^{z_{j}} \tilde{\phi}_{j}\left(b_{j}\right) d b_{j}\right)=\left(\alpha_{j}+\beta_{j}\right) \int_{0}^{z_{j}} \tilde{\phi}_{j}\left(b_{j}\right) d b_{j}-\beta_{j}=0 .
\end{gathered}
$$

Hereof

$$
\left.\int_{0}^{z_{j}} \tilde{\phi}_{j}\left(b_{j}\right) d b_{j}\right)=\frac{\beta_{j}}{\alpha_{j}+\beta_{j}} .
$$

The resulting equation is solved numerically with respect to $z_{j}$, and if the function $\tilde{\phi}_{j}\left(b_{j}\right)$ is integrable, then analytically. Let, for example, the distribution density $\tilde{\phi}_{j}\left(b_{j}\right)$ corresponds to the Rayleigh law, that is,

$$
\tilde{\phi}_{j}\left(b_{j}\right)=\frac{b_{j}}{\sigma^{2}} \exp \left\{-\frac{b_{j}^{2}}{2 \sigma^{2}}\right\} \text {. }
$$

In this case, the equation with respect to $z_{j}$

$$
1-\exp \left\{-\frac{z_{j}^{2}}{2 \sigma^{2}}\right\}=\frac{\beta_{j}}{\alpha_{j}+\beta_{j}},
$$

from which

$$
\exp \left\{-\frac{z_{j}^{2}}{2 \sigma^{2}}\right\}=1-\frac{\beta_{j}}{\alpha_{j}+\beta_{j}}=\frac{\alpha_{j}}{\alpha_{j}+\beta_{j}}, \quad z_{j}= \pm \sigma \sqrt{2} \ln \frac{\alpha_{j}+\beta_{j}}{\alpha_{j}}
$$


Choosing a positive root

$$
z_{j}^{(0)}=\sigma \sqrt{2} \ln \frac{\alpha_{j}+\beta_{j}}{\alpha_{j}}, j=1,2, \ldots, n
$$

The considered task becomes significantly more difficult if the parameters of the membership function of a fuzzy demand value are not clearly defined. Let's suppose that this demand $x$ is given by a triangular fuzzy number with the membership function (15)

$$
\mu_{x}(x)= \begin{cases}0, & x<a, \\ \frac{x-a}{c-a}, & a \leq x<c, \\ \frac{b-x}{b-c}, & c \leq x \leq b, \\ 0, & x>b .\end{cases}
$$

Let's suppose further, in the practical determination of the parameters $(a, b, c)$ of the corresponding membership function, it turns out that these parameters can't be defined precisely. If fuzzy numbers are used to describe these parameters, the original number $x$ turns out to be bifuzzy. Such fuzzy numbers are introduced in [11], but the formal technologies for performing operations on them are not defined. In connection with this, let's consider the problem of describing the membership function of a bifuzzy number [12].

Let, for example, the membership function of a fuzzy number $x$ has the form (15). Suppose now that the parameters of this membership function are fuzzy numbers. Let's assume, for simplicity, that, in particular, the parameter a of the membership function $\mu_{x}(x)$ is a triangular fuzzy number with the membership function $\mu_{a}(a)$ having the form

$$
\mu_{a}(a)= \begin{cases}0, & a<a_{1}, \\ \frac{a-a_{1}}{c_{1}-a_{1}}, & a_{1} \leq a<c_{1}, \\ \frac{b_{1}-a}{b_{1}-c_{1}}, & c_{1} \leq a \leq b_{1}, \\ 0, & a>b_{1} .\end{cases}
$$

Let's consider the situation. A fuzzy number $x$ with the membership function (15) corresponds to the degree of belonging to the universe $X=[a, b]$, equal to (if $a \leq x<c$ ) a crisp number $\frac{x-a}{c-a}$. If now $a$ is a fuzzy number, then this degree of membership also becomes a fuzzy number, because with fuzzy $a$ a variety of membership functions $\mu(x, a)$ arise, each of which for a fixed number $x$ sets the degree of number $x$ membership to the new universe $X=\left[a_{1}, b\right]$.

Let's find the membership function of a fuzzy number $u=(x-a) /)(c-a)$, which determines the degree of belonging of the bifuzzy number $x$ to the universe $X=\left[a_{1}, b\right]$, taking into account the parameter $a$ ambiguity.

Using standard technology [5-9] and rules for performing operations on fuzzy numbers:

$$
\begin{gathered}
u=f(a)=\frac{x-a}{c-a}, \\
a=f^{-1}(u)=\frac{u c-x}{u-1} .
\end{gathered}
$$

In this case 


$$
u \in\left[\frac{x-a_{\max }}{c-a_{\max }}, \frac{x-a_{\min }}{c-a_{\min }}\right] .
$$

Then $\mu(u)=\mu_{a}(u)$.

The analytical expression for $\mu_{a}(u)$ depends on the choice of value $x$.

Let $x>b_{1}$. Then $a \in\left[a_{1}, b_{1}\right]$.

At the same time let's obtain

$$
\mu_{a}(u)= \begin{cases}0, & u<\frac{x-b_{1}}{c-b_{1}}, \\ \frac{u\left(c-b_{1}\right)-\left(x-b_{1}\right)}{\left(b_{1}-c_{1}\right)-u\left(b_{1}-c_{1}\right)}, & \frac{x-b_{1}}{c-b_{1}} \leq u \leq \frac{x-c_{1}}{c-c_{1}}, \\ \frac{\left(x-a_{1}\right)-u\left(c-a_{1}\right)}{\left(c_{1}-a_{1}\right)-u\left(c_{1}-a_{1}\right)}, & \frac{x-c_{1}}{c-c_{1}}<u \leq \frac{x-a_{1}}{c-a_{1}} \\ 0, & u>\frac{x-a_{1}}{c-a_{1}} .\end{cases}
$$

Now let $c_{1} \leq x \leq b_{1}$. Then

$$
\mu_{a}(u)= \begin{cases}0, & u<0, \\ \frac{u(c-x)}{\left(x-c_{1}\right)-u\left(x-c_{1}\right)}, & 0 \leq u \leq \frac{x-c_{1}}{c-c_{1}}, \\ \frac{\left(x-a_{1}\right)-u\left(c-a_{1}\right)}{\left(c_{1}-a_{1}\right)-u\left(c_{1}-a_{1}\right)}, & \frac{x-c_{1}}{c-c_{1}}<u \leq \frac{x-a_{1}}{c-a_{1}}, \\ 0, & u>\frac{x-a_{1}}{c-a_{1}} .\end{cases}
$$

Finally if $a_{1}<x<c_{1}$, then

$$
\mu_{a}(u)= \begin{cases}0, & u<0, \\ \frac{\left(x-a_{1}\right)-u\left(c-a_{1}\right)}{(1-u)\left(x-a_{1}\right)}, & 0<u<\frac{x-a_{1}}{c-a_{1}} \\ 0, & u>\frac{x-a_{1}}{c-a_{1}}\end{cases}
$$

The technologies discussed above make it possible to obtain models of deep uncertainty in problems of logistics based on analytical descriptions of the membership function of fuzzy variables that reflect the state and dynamics of the behavior of real objects.

The obtained relation for bifuzzy demand allows to solve the following problem in terms of interval mathematics: to find the range of demand $X$, values for which the value and the membership function $\mu(u)$ will not be lower than the specified

$$
x \in\left[x_{\min }(u), x_{\max }(u)\right] .
$$

The boundaries of the range are determined by the ratios 


$$
u=\frac{x_{\min }(u)-a_{1}}{c-a_{1}}=\frac{b-x_{\max }(u)}{b-c},
$$

from which

$$
x_{\min }(u)=a_{1}+u\left(c-a_{1}\right), \quad x_{\max }(u)=b-u(b-c) .
$$

Then, for any particular order $z$ value, the range of values for the unrealized balance can be determined.

$$
r_{\text {rem }} \in\left[z-x_{\max }(u), z-x_{\min }(u)\right]
$$

as well as the range of possible deficit

$$
r_{d e f} \in\left[x_{\min }(u)-z, x_{\max }(u)-z\right]
$$

Corresponding storage costs and losses from deficit are equal

$$
\begin{aligned}
& R_{1}(z, u)=\alpha r_{\text {rem }}, \\
& R_{2}(z, u)=\beta r_{\text {def }} .
\end{aligned}
$$

Substituting (20)-(22) into (23), let's obtain

$$
\begin{gathered}
R_{1}(z, u) \in \alpha\left[z-x_{\max }(u), z-x_{\min }(u)\right]= \\
\alpha\left[z-(b-u(b-c)), z-\left(a_{1}+u\left(c-a_{1}\right)\right] ;\right. \\
R_{2}(z, u) \in \beta\left[x_{\min }(u)-z, x_{\max }(u)-z\right]= \\
\beta\left[a_{1}+u\left(c-a_{1}\right)-z, b-u(b-c)-z\right] .
\end{gathered}
$$

At the same time, the range of possible values of total losses for given $(z, u)$ is determined by the ratio

$$
\begin{gathered}
R_{\Sigma}(z, u) \in\left[\alpha\left(z-x_{\max }(u)\right)+\beta\left(x_{\min }(u)-z\right), \alpha\left(z-x_{\min }(u)\right)+\beta\left(x_{\max }(u)-z,\right]=\right. \\
=\left[\beta\left(x_{\text {min }}(u)-\alpha x_{\text {max }}(u)-z(\beta-\alpha), \beta x_{\text {max }}(u)-\alpha x_{\text {min }}(u)-z(\beta-\alpha)\right] .\right.
\end{gathered}
$$

Relation (24) allows to formulate the following interval problem of choosing a rational value of the volume of the ordered product: find $z$ the maximum value of the total losses $R_{\Sigma}(z, u)$ that does not exceed the allowable value $R_{\Sigma}^{0}(z, u)$. The sought value $z^{(0)}$ is determined, taking into account (24) by solving the inequality:

$$
\beta x_{\max }(u)-\alpha x_{\min }(u)-z(\beta-\alpha) \leq R_{\Sigma}^{0},
$$

From which

$$
z \geq \frac{\beta x_{\max }(u)-\alpha x_{\min }(u)}{\beta-\alpha} .
$$

The modernization of the mathematical scheme for calculating the rational value of the ordered product, taking into account the bifuzzy of demand for each consumer, necessitates a corresponding modernization and criterion (4) of the initial supply management problem. At the same time, it is natural to reformulate this task as follows: find sets $z=\left(z_{j}\right)$ and $X(Z)=\left\{x_{i j}\left(z_{j}\right)\right\}$, minimizing 


$$
\left(x_{i j}\left(z_{j}\right)\right)=\sum_{i=1}^{m} \sum_{j=1}^{n} c_{i j} x_{i j}\left(z_{j}\right)+\sum_{j=1}^{n}\left(z_{j}-z_{j}^{(0)}\right)^{2}
$$

and satisfying constraints (5)-(8).

The most simple and effective procedure for solving this problem is implemented by the Nelder-Mead method.

\section{The results of the development of solutions to the management problem in a distributed consumption system}

The paper deals with the problem of supply management in a distributed system "suppliers-consumers". The traditionally used procedure for solving this problem is a two-step process. At the first stage, for each consumer, taking into account the demand for the product being sold, the task of calculating the rational value of the ordered product is minimized, minimizing the cost of storing the unrealized balance and losses from a possible shortage. At the second stage, the usual transport problem of linear programming is solved taking into account the formed set of orders for the product delivered to the points of consumption. An alternative method for solving the original problem is proposed using a complex criterion that takes into account the cost of transporting and selling the delivered product. The implementation of this approach provides a tangible gain in the total cost of sales of the product produced in a single production-delivery-consumption logistic system. This gain grows as the volume of produced and sold product increases. The obvious advantages of the proposed approach are confirmed by calculating the efficiency of a simple model of the system under consideration, which contains two production points and five consumption points. At the same time, a matrix of average delivery costs of a unit of product for each pair "producer-consumer" and a vector of rational values of the ordered product are specified. The problem was solved using the traditional two-step procedure, and then the proposed method. The gain in the total cost of sales amounted to $8 \%$. With an increase in the total volume of the product sold twice the gain increased to $11.2 \%$.

\section{Discussion of the results of solving the problem of transportation management in the logis- tic system under uncertainty conditions}

A method is proposed for solving the problem of supply management in a production-delivery-consumption logistics system, taking into account the modification of the traditional theoretical probabilistic mathematical model for describing the uncertainty of the initial data. It is shown that a more adequate is a model that uses their binaries. The optimization problem arising from this is not solved by traditional methods. In the paper, the desired solution is obtained in terms of interval mathematics. The direction of further research: the development of exact methods for solving optimization problems, the parameters of which are not clearly defined $[13,14]$.

\section{Conclusions}

1. A method is developed for transportation management in a distributed production-delivery-consumption logistic system under conditions of high uncertainty in the source data, which is described bifuzzy.

2. Unparalleled technology for calculating membership functions for fuzzy numbers, the numerical parameters of which themselves are not clearly described, is developed.

3. A method is developed for solving a nontrivial optimization problem, the parameters of which are given bifuzzy. In the well-known literature, such problems were not considered. To solve the problem, an interval approach is proposed, which determines the approximate solution of the problem, which asymptotically approaches the exact solution.

\section{References}

[1] Dantsig, Dzh. (1966). Lineynoe programmirovanie, ego obobscheniya i primeneniya. Moscow: Progress, 602.

[2] Birman, I. Ya. (1962). Transportnaya zadacha lineynogo programmirovaniya. Moscow, 270. 
[3] Gol'shteyn, E. G., Yudin, D. B. (1969). Zadachi lineynogo programmirovaniya transportnogo tipa. Moscow: Nauka, 482.

[4] Mirotin L. B. (Ed.) (2003). Transportnaya logistika. Moscow: Ekzamen, 512.

[5] Zadeh, L. A. (1965). Fuzzy sets. Information and Control, 8 (3), 338-353. doi: https://doi.org/10.1016/s0019-9958(65)90241-x

[6] Kofman, A. (1982). Vvedenie v teoriyu nechetkih mnozhestv. Moscow: Radio i svyaz', 432.

[7] Orlovskiy, S. A. (1981). Problemy prinyatiy resheniy pri nechetkoy iskhodnoy inforamtsii. Moscow: Nauka, 206.

[8] Raskin, L. G., Seraya, O. V. (2008). Nechetkaya matematika. Hharkiv: Parus, 352.

[9] Leonenkov, A. V. (2005). Nechetkoe modelirovanie v srede MATLAB i fuzzyTECH. Sankt-Peterburg: BHV-Peterburg, 736.

[10] Karpenko, V. V., Akhmadov, R. H. (2015). Transportnaya zadacha lineynogo programmirovaniya s nechetkim sprosom. Visnyk Natsionalnoho tekhnichnoho universytetu „KhPI”. Seriya: Systemnyi analiz, upravlinnia ta informatsiyni tekhnolohiyi, 58, 99-103.

[11] Lyu, B. (2005). Teoriya i praktika neopredelennogo programmirovaniya. Moscow: BINOM, 416.

[12] Seraya, O. V., Raskin, L. G. (2009). Binechetkie modeli neopredlennosti v zadachah issledovaniya slozhnyh sistem. Systemnyi analiz ta informatsiyni tekhnolohiyi: tez. dopov. Mizhnarodnoi naukovo - tekhnichnoi konferentsiyi. Kyiv, 37.

[13] Raskin, L., Sira, O. (2016). Method of solving fuzzy problems of mathematical programming. Eastern-European Journal of Enterprise Technologies, 5 (4 (83)), 23-28. doi: https://doi.org/10.15587/1729-4061.2016.81292

[14] Raskin, L., Sira, O. (2016). Fuzzy models of rough mathematics. Eastern-European Journal of Enterprise Technologies, 6 (4 (84)), 53-60. doi: https://doi.org/10.15587/1729-4061.2016.86739 